\title{
RESISTANCE AND SUSCEPTIBILITY OF MILKWEED: COMPETITION, ROOT HERBIVORY, AND PLANT GENETIC VARIATION
}

\author{
Anurag A. Agrawal ${ }^{1}$ \\ Department of Botany, 25 Willcocks Street, University of Toronto, Toronto, Ontario, Canada M5S 3B2
}

Abstract. Beetles in the genus Tetraopes share a long evolutionary history with milkweeds (Asclepias spp.), feeding on roots as larvae and leaves as adults. Despite their extreme specialization on milkweed, Tetraopes require drying grass stems as oviposition sites, even though they do not consume grass. The natural history of the interaction suggests that herbivory may be likely only when milkweeds are in close proximity to grasses. Theory also predicts that two stresses on plants, competition and herbivory, may have non-additive negative impacts on correlates of fitness. In field experiments conducted over two years, I followed the consequences of grass competition and beetle attack for herbivory, growth, and reproduction of milkweed, and reciprocal effects of milkweed on grass in common gardens. To assess the effect of milkweed traits on beetles, I conducted a quantitative genetic experiment using full-sibling families of milkweed and measured the effects of putative resistance traits on the abundance of Tetraopes adults. Milkweeds growing next to grass were initially unaffected in growth but suffered $10 \%$ greater leaf herbivory by adult Tetraopes than did milkweeds growing alone. This effect was caused by direct attraction of beetles to grass, not by a competitive modification of milkweed's phenotype. In late summer of the first growing season, when Tetraopes naturally oviposits, I experimentally added larvae to milkweed roots with and without grass competition. Within a month, I detected an interaction between competition and herbivory: neither had an individual impact, but jointly they reduced milkweed growth. In spring of the second growing season, when Tetraopes had completed development, I again found strong evidence for a non-additive effect of competition and herbivory together, severely reducing plant growth compared to their individual effects. Root herbivory induced a plant response that reduced the abundance of leaf-mining flies by $40 \%$, but only for milkweeds with grass competition. Neither competition nor herbivory affected the production of defensive latex, cardenolides, or carbon, but they interacted to affect leaf nitrogen content. Thus, although trait-mediated indirect interactions were implicated in the effect of competition and root herbivory on leaf miner abundance, I did not uncover the mechanism. In the final harvest, beetle herbivory reduced reproductive characters (fruit production, fruit mass, aboveground biomass) by 20 $30 \%$, whereas competition had negligible effects. The net interaction effect for grass was competitive, with a $23 \%$ reduction in grass biomass caused by milkweed in the absence of herbivory. However, the presence of beetle herbivory on milkweed roots completely alleviated the competitive effect of milkweed on grass. Thus, the associational effect of grass on milkweed resulted in milkweed suffering the non-additive effects of competition and herbivory, whereas grass enjoyed competitive release by facilitating its neighbor's herbivore. Many traits of milkweed (e.g., growth, reproduction, and several resistance traits) showed variation among 23 full-sibling families, indicating that competitive ability and resistance may be subject to natural selection. A multiple regression analysis on family means revealed that leaf trichome density and nitrogen content were negatively genetically correlated with abundance of Tetraopes adults, but probability of flowering and plant height were positively associated. Leaf miners were most strongly negatively affected by latex and trichomes. Thus, complex interactions among competition, root herbivory, and plant genetic variation affect the herbivore and plant community and may result in diffuse coevolution between milkweed and its herbivores. I present a general model that predicts the conditions in which plant-plant interactions result in net competition or facilitation.

Key words: Asclepias syriaca; associational susceptibility; cardenolides; competitive release; diffuse coevolution; induced plant resistance; latex; leaf miner Liriomyza asclepiadis; plant-insect interactions; Tetraopes tetraophthalmus; trait-mediated indirect effect; trichomes.

Manuscript received 4 September 2003; revised 23 December 2003; accepted 6 January 2004. Corresponding Editor: R. F. Denno.

${ }^{1}$ E-mail: anurag.agrawal@utoronto.ca

\section{INTRODUCTION}

A trophic view of the world suggests that green plants, as primary producers, face two major threats: competition for resources and consumption by animals 
and microbes. Although Hairston et al. (1960) argued that plant productivity was only limited by competition, and not herbivory, they were essentially wrong. Indeed, both plant competition (Goldberg and Barton 1992) and insect herbivory (Marquis 1992) have been shown to reduce the productivity or performance of plants in many species. Given the fact that these threats are ubiquitous in space and time, plant ecologists have long recognized the importance of studying the joint effects of competition and herbivory (Louda et al. 1990, Rees and Brown 1992, Gurevitch et al. 2000, Hambäck and Beckerman 2003). I will outline three lines of theory that have predicted interactions or non-additive effects between neighboring plants and herbivory.

First, competition may alter the levels of herbivory experienced by a host plant. Theory predicts that plants may negatively or positively interact via the altered attraction or numerical response of enemies (i.e., apparent competition; Holt 1977, Holt and Kotler 1987, Connell 1990). Empirically, ecologists have referred to these effects as associational resistance and susceptibility, because a plant neighbor affects the level of attack on a focal plant (Tahvanainen and Root 1972, Atsatt and O'Dowd 1976, Andow 1991, Karban 1997, Hambäck et al. 2000, White and Whitham 2000, Rand 2003). Associational resistance occurs through a variety of mechanisms, including chemical or visual masking by the competitor (Prokopy and Owens 1983, Visser 1986), repellency (Atsatt and O'Dowd 1976, Herrera 1991), or a poor-quality alternative resource (Morrow et al. 1989, Hjältén et al. 1993). Although much less studied, associational susceptibility presumably occurs via the same types of mechanisms (e.g., odors, visual cues), but with the opposite effect on the focal plant (Parker and Root 1981, Thomas 1986, Karban 1997, White and Whitham 2000).

The second way in which competition and herbivory have been predicted to interact involves neighboring plants affecting resistance traits of a focal plant $(\mathrm{Ci}-$ pollini 2004). Plant competition may affect constitutive traits or induced responses, which are activated following initial herbivory (Karban and Baldwin 1997). Collectively, when either plant competition or herbivory changes the plant's phenotype and this influences subsequent feeders, a trait-mediated indirect effect has occurred (Agrawal 2001). More generally, trait-mediated effects occur whenever one interaction causes a change in the phenotype of an organism, which influences other interactions (Abrams 1995, Peacor and Werner 2001, Callaway and Pennings 2003). Karban and colleagues (1989) found that cotton plants showed lower induced resistance when growing in competitive compared to noncompetitive environments. These authors proposed a model whereby the strength of plant resistance decreases as competition increases, due to resource limitation. There have been a few tests of this model (Karban 1993, Hjältén et al. 1994, Cipollini and Bergelson 2001), but so far no general picture has emerged. Although plant competition frequently may reduce resources available to plants, and thus investment in chemical resistance traits, competition may also affect primary compounds in leaves, i.e., increased nitrogen (Jansen and Stamp 1997); leaf traits such as trichomes (Young and Smith 1980); stem architecture (Agrawal and Van Zandt 2003); and overall plant size (Goldberg and Barton 1992). Thus, the net effects of competition and herbivory via changes in plant traits are still unclear.

Third, competition and herbivory can have a nonadditive effect on a focal host plant, even when competition does not alter the levels of herbivory, because the imposition of one may affect the plant's ability to cope with the second. For example, herbivores are expected to reduce not only the leaf area available for photosynthesis, but also the growth function of plants, potentially altering competitive interactions (Rees and Brown 1992). Two hypotheses, the cumulative stress model and the compensatory continuum hypothesis, have used this logic to predict that plants free from competition will be better able to tolerate herbivory than plants experiencing competition (Harris 1981, Maschinski and Whitham 1989, Tiffin 2002). In a recent review of experiments that factorially manipulated competition and herbivory, only two out of 10 studies showed a significant interaction between the effect of the competition and herbivory on fitness components (Hambäck and Beckerman 2003). In one of these studies, the joint impact of competition and herbivory was greater than additive (synergistic), as predicted (Friedli and Bacher 2001), but in the other study the pattern was reversed, with competition and herbivory having a weaker (substitutive) impact together than expected by the independent effects (Dormann et al. 2000).

The extent to which competition and herbivory interact will depend, to some extent, on the host specificity of the herbivore (Holt and Kotler 1987, Louda et al. 1990). Where herbivores are host specific, as opposed to generalized, plant competition is more likely to result in reduced herbivory (i.e., associational resistance) on the focal plant (Andow 1991). Conversely, from the competitor's perspective, competition will be alleviated by herbivory that is specific to the focal plant, because herbivory indirectly increases resources for the competitor (Fig. 1; see Peacor and Werner 2001).

The three different paths by which competition and herbivory may interact have rarely been linked in a single study system. Hambäck and Beckerman (2003) refer to the different types of studies as "herbivore" and "plant" based. In herbivore-based studies, the behavior and abundance of herbivores are measured when plants are grown alone or with competitors (i.e., studies of associational or trait-mediated effects). In plantbased studies, fixed levels of competition and herbivory are employed to estimate effects on plant growth and reproduction (i.e., tests of the cumulative stress model). 
Tetraopes

(herbivore)

$\uparrow$

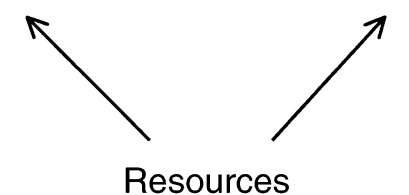

FIG. 1. A trophic view of the interactions between two plant competitors and a host-specific herbivore. Arrows indicate energy flow. The many possible indirect effects are not indicated, but three examined in this study include: resource competition between the plants, facilitation of Tetraopes by grass and its effects on milkweed, and benefits to grass from the consumption of milkweed roots by Tetraopes.

Given the many possible direct and indirect effects even in simple food webs (Fig. 1), only an integrated approach is likely to accurately reflect the nature of interactions between competition and herbivory. Although plant competition and herbivory affect the plant phenotype and may mediate interactions with herbivores, genetic variation for resistance traits in plants may also affect plant-herbivore interactions (Marquis 1992, Stinchcombe and Rausher 2001, Tiffin 2002, Agrawal and Van Zandt 2003). Thus, understanding how genetic variation for traits functions in the backdrop of community interactions (i.e., competition and herbivory) is important in understanding the relative contributions of genotype and environment in resistance and susceptibility.

In this study, I examine the interactions among herbivorous Tetraopes tetraophthalmus beetles, Liriomyza asclepiadis leaf-mining flies, and milkweed plants, as they are affected by plant competition and genetic variation for resistance traits. Despite their host specificity on milkweed, Tetraopes beetles require drying grass stems as oviposition sites, even though they do not consume grass. The natural history of this interaction suggests that plant competition and herbivory may be associated. Given the multitude of direct and indirect effects possible, I used the available natural history, concepts, and theory to generate the following predictions:

1) Because grasses provide Tetraopes with an essential oviposition resource, Tetraopes will be more likely to damage milkweeds next to grass than milkweeds free from grass competition.

2) Plant competition will reduce milkweed's investment in defensive traits and subsequent resistance to other herbivores (i.e., leaf miners) in the community.
3) Competition and herbivory should synergistically reduce the growth and reproduction of milkweed.

4) Grasses competing with milkweed will indirectly benefit from the herbivory by Tetraopes on milkweed (i.e., grasses will experience competitive release).

5) Given the shared evolutionary history of milkweed and its specialist herbivores, genetic families of milkweed should vary in resistance traits that correlate with attack.

\section{Materials And Methods Natural history}

This study was conducted at the University of Toronto's Koffler Scientific Reserve at Jokers Hill ${ }^{2}$, in southern Ontario, Canada $\left(44^{\circ} 03^{\prime} \mathrm{N}, 79^{\circ} 29^{\prime} \mathrm{W}\right)$, henceforth Jokers Hill. At the site, common milkweed (Asclepias syriaca) is abundant in old-field habitats. $A$. syriaca is a native perennial plant that reproduces by clonal production of underground stems and by sexual reproduction via hermaphroditic flowers. Seeds from a single fruit of $A$. syriaca are full siblings because of the pollinia pollination system of milkweeds; i.e., a single pollen sac or pollinium sires all of the seeds from a flower (Gold and Shore 1995).

Milkweed's well-known toxicity and arsenal of defenses limit the herbivore community to $\sim 10$ species of mostly host-specific insects (Malcolm 1991, Agrawal and Malcolm 2002). Probably the two most potent aspects of plant defense in milkweed are the production of cardiac glycosides (cardenolides) and latex. Cardenolides are bitter-tasting steroids that have toxic effects on most animals. Cardenolides act by disrupting the sodium and potassium flux in cells and occur in all milkweed tissues, including the latex (Malcolm 1991). The sticky white latex of milkweed is copiously exuded upon damage to the tissues. This latex is delivered via specialized canals (laticifers) to most plant parts and has been strongly implicated as a physical defense that impedes feeding by herbivores (Dussourd 1999).

Cerambycid beetles in the genus Tetraopes share a long evolutionary history with Asclepias spp. and the herbivore and plant groups exhibit parallel phylogenies (Farrell and Mitter 1998). At our site, Tetraopes tetraophthalmus adults emerge from pupation in late June to early July. Beetle distribution can be very dense, with more than 20 adults $/ \mathrm{m}^{2}$ of milkweed plants (personal observations; Fig. 2). In July, beetles frequently can be seen mating on milkweed and consuming the leaves in a characteristic pattern that follows deactivation of the laticifers (Dussourd 1999). Observational and experimental studies have suggested that adult beetles congregate at sites with abundant milkweed flowers, although this is not due to a preference for feeding on flowers (Matter et al. 1999, Matter 2001, Reagel et al. 2002). Despite the host specificity of Tetraopes, females oviposit in the drying flowering stems of thick-

\footnotetext{
${ }^{2}\langle$ http://www.zoo.utoronto.ca/jokershill $\rangle$
} 


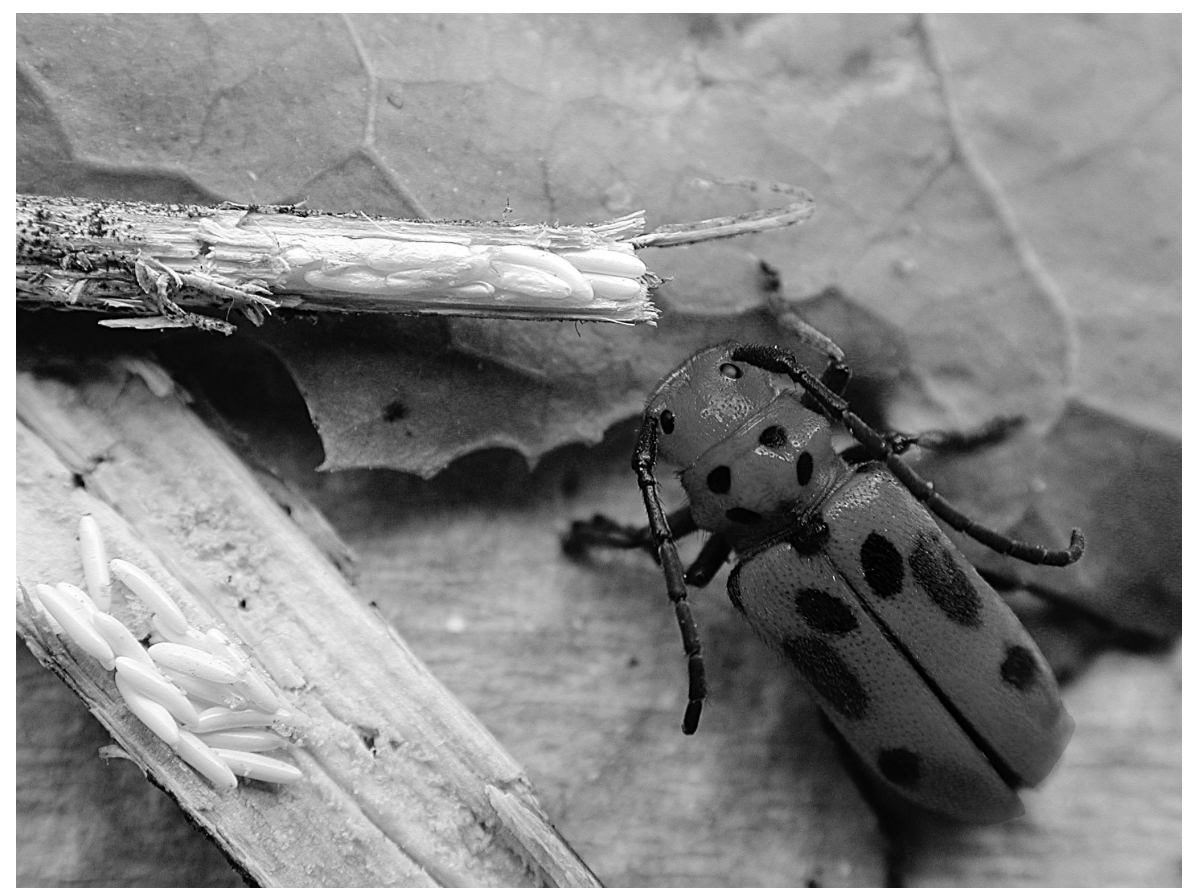

FIG. 2. An adult Tetraopes tetraophthalmus and the eggs that she deposited in a plant stem.

bodied grasses and occasionally in thin-bodied forb stems (Gardiner 1961; Matter 2001, personal observations). After chewing a small hole in the grass stems, females will deposit clutches of 10-15 eggs (personal observations). After 10-12 days, eggs hatch into larvae that drop to the soil and burrow down, seeking milkweed roots. Larvae consume only roots and underground stems of milkweed and overwinter as large prepupae.

Because I was also interested in how plant competition and herbivory would alter subsequent herbivory (i.e., effects on plant resistance), I examined the colonization of milkweed by other members of the herbivore community. In this study I focus on Liriomyza asclepiadis, a leaf-mining fly host-specific to milkweed, that was extremely abundant on plants during the study. Monarch butterflies and caterpillars were rare, probably due to a catastrophic die-off of overwintering adults in Mexico in early 2002 (Brower et al. 2004).

In the fields where milkweed typically grows, the majority of neighboring plants are introduced grasses. At my study site, most habitats are dominated by thickbodied grasses that grow interspersed with milkweed. At other more sandy sites, however, milkweed can grow free of grass competition. To study the independent and combined effects of competition and herbivory, I focused on one of these grasses, the perennial exotic, Bromus inermis. Bromus is the dominant grass in regenerating old fields at Jokers Hill and is suitable for Tetraopes oviposition. Although this exotic grass does not share a long evolutionary history with milkweed, it has been a dominant old-field grass for decades and is similar to native thick-bodied grasses.

\section{Effects of grass competition on herbivory and the net effects on plant performance}

Seeds from 14 full-sibling families (individual fruits from separate milkweed plants) were collected from wild populations at Jokers Hill. Seeds were nicked, germinated on moist filter paper in petri dishes, and grown for 3 weeks in 500-mL plastic pots and Pro-Mix BX soil (Red Hill, Pennsylvania, USA) in a growth chamber. Each plant received $\sim 0.6 \mathrm{~g}$ of slow-release Nutricote fertilizer pellets (13:13:13 N:P:K; Vicksburg Chemical, Vicksburg, Mississippi, USA). I transplanted the plants to a common garden in a tilled old field at Jokers Hill on 13 June 2001. In the common garden, plants were transplanted to 6-L plastic pots (at 1-m spacing) filled with soil from the tilled field. Pots were sunk in the ground so that the top of the pot was flush with the soil. Pots were used to contain lateral spread of each clonal plant; in the second year of growth, milkweed plants typically emerge as multiple stems, sometimes $>1 \mathrm{~m}$ away from the original plant if not restricted. The ground around the pots was covered with a thin sheet of water-permeable landscaping fabric to reduce growth of weeds.

In the first growing season, plants were randomly assigned to one of four treatments ( $n=32-35$ plants per treatment) in a $2 \times 2$ factorial design crossing presence of root herbivory with grass competition. The competition treatment involved planting 10 recently germinated Bromus seedlings around the milkweed 
plant (within the pot); this density is lower than that of typical old fields at Jokers Hill and milkweeds were 15-20 cm tall when grasses were germinated. The herbivory treatment was achieved by introducing larvae to the base of the focal milkweed plants. On each of the evenings of 7 and 8 August 2001, I introduced seven freshly hatched first-instar larvae per milkweed plant assigned to the herbivory treatment. This number of larvae was based on the clutch size frequently observed per oviposition (10-15 eggs). Naturally occurring $T e$ traopes adults did not oviposit in the common garden, probably because the grass plants did not produce large flowering stems.

\section{Measurements and analyses}

First growing season.-Before the root herbivory treatment was imposed, I censused the percentage of leaves with herbivory by Tetraopes on each plant. Because herbivory by Tetraopes is quite characteristic and regular $(\sim 10 \%$ of a leaf is consumed from the tip inward), this measure of herbivory probably reflects the leaf area consumed. One month after the Tetraopes larvae were introduced to the roots, near the end of the first growing season, I measured the heights of the plants as a nondestructive indication of plant growth. Plant height is correlated with dry vegetative biomass ( $r=0.58, n=538, P<0.001$; A. Agrawal, unpublished data). Plants were not further manipulated and were allowed to overwinter naturally.

Second growing season.-Tetraopes typically pupates and emerges in mid-spring. Thus, to estimate the impact of the root herbivory and competition, I measured three traits of milkweed in late May, as new milkweed stems were emerging: (1) the number of stems, (2) the sum of the heights of the stems, and (3) the sum of the widths of these stems at the base of the plants.

Toward the end of the second growing season, before plants were beginning to senesce, I censused the percentage of leaves with herbivory by Tetraopes on each plant and the number of leaf mines initiated by L. asclepiadis. To estimate how grass competition and root herbivory affected resistance traits of milkweed, at the same time I collected a single young, but fully expanded, undamaged leaf from the plants to measure the production of cardiac glycosides, latex, and leaf carbon and nitrogen content. Details on the measurement of these traits are provided in Appendix A.

When the first plants began to senesce, I separately harvested all fruits and aboveground vegetative parts. These materials were dried in a large forced-air oven at $45^{\circ} \mathrm{C}$. I report aboveground vegetative biomass, number of fruits, and dry mass per fruit as components of plant performance. I was unable to harvest underground biomass because most plants had sent large, deep roots through the drainage holes in the pots.

Analyses of plant traits.-Effects of grass competition, root herbivory, and milkweed family on milkweed traits were analyzed using sets of multivariate analyses of variance (MANOVA). I employed a MANOVA approach because (1) the three reproductive measures were potentially correlated, and (2) the multivariate approach is more powerful than univariate analyses because it simultaneously incorporates several response variables (Scheiner 1993). I proceeded to interpret the univariate analyses to decompose the results when the MANOVA was significant. For univariate analyses, I employed SAS PROC MIXED using family as a random effect and grass competition and root herbivory as fixed effects. As suggested by the SAS Institute (1999), I employed the likelihood ratio $\chi^{2}$, a onesided, single degree of freedom test, for random effects. The likelihood ratio $\chi^{2}$ tests the hypothesis that the variation due to the random effect is greater than 0 .

All plant trait data were log-transformed because I was examining the multiplicative null model for the interpretation of the interaction term between grass competition and root herbivory. Because herbivores are expected to reduce not only the root biomass, but also the growth function of plants, the multiplicative model is most appropriate (Rees and Brown 1992). The multiplicative interpretation of the interaction term also implies that each factor has the same proportional effect, irrespective of the influence of other factor (Reader and Bonser 1998). I did not include the interaction between milkweed full-sibling families and the other main effects because (1) family was primarily included as a blocking factor to account for variance associated with genetic variation in plant traits, and (2) I had low replication for some of the families in the design, making analysis of the interaction terms problematic. A separate, much larger, experiment was designed to test for genetic variation in plant resistance.

Light measurements.-I measured the amount of photosynthetically active radiation $(400-700 \mathrm{~nm}$, in micromoles of photons per square meter per second) reaching the base of milkweed plants with and without grass neighbors to assess the potential for light competition.

\section{Mechanisms of effects of grass competitors on Tetraopes}

Grass competition may change some aspect of the milkweed phenotype, making it more attractive to beetles (i.e., trait-mediated indirect effect), or beetles may simply be attracted to grass because it is an oviposition substrate. To address the possible mechanisms that increase damage to milkweed plants next to grass, I conducted a choice test. I grew milkweed plants from seed in 500-mL pots with Pro-Mix soil. After one month of growth in an outdoor mesh exclosure, milkweed plants were paired for size (most plants were $20-25 \mathrm{~cm}$ tall). In a randomly chosen pot of the pair, I inserted 10 drying flower stems of Bromus, cut from wild plants growing in the area. This manipulation alters the finescale neighborhood of the milkweed without altering 
the plant's phenotype, because all plants were grown in the same environment, without grass competitors. Each of 38 pairs of plants was placed in a $1-\mathrm{m}^{3}$ mesh cage with a single adult Tetraopes. The cages were erected on bare soil in a tilled field, pairs of plants were spaced $50 \mathrm{~cm}$ apart within each cage, and the position of plants, with or without grass stems, was randomized. After 48 hours I examined leaf herbivory on the milkweed plants by noting which plant in the pair had greater levels of damage. In cases in which this was ambiguous, an acetate grid was employed to detect which plant had greater levels of damage. In seven cages, no herbivory was detected on either plant and these replicates were omitted. The effect of grass neighbors on herbivory was then analyzed using a $G$ test with William's correction, employed to detect differences in choice assays (Sokal and Rohlf 1995).

Effects of competition and herbivory on the grass

In addition to the factorial treatments crossing competition and root herbivory, a treatment of Bromus alone (10 stems per replicate, $n=36$ ) was interspersed and randomly assigned in the common garden of the main experiment. This treatment was established at the same time that grasses were planted in the main experiment next to milkweeds. At the end of the two years of growth, the aboveground biomass of grass was harvested from the three treatments with grass (grass alone, grass with milkweed, and grass with milkweed and Tetraopes). Differences in the aboveground dry biomass of the grass were analyzed with one-way ANOVA, with the prediction that Tetraopes herbivory should reduce the competitive effects of milkweed on grass (Fig. 1).

In addition, half of the grass-alone treatments received Tetraopes larvae to confirm that Tetraopes larvae do not consume grass. Dry grass biomass was compared using a $t$ test $(3.1 \pm 0.3 \mathrm{~g}$ with beetles, $3.4 \pm$ $0.5 \mathrm{~g}$ without beetles, mean $\pm 1 \mathrm{SE} ; t=0.562$, df $=$ $34, P=0.577)$. Because there was no difference, I pooled the grass-alone samples, with and without $T e$ traopes larvae, for all subsequent analyses.

Genetic variation in milkweed for effects on abundance of Tetraopes adults and leaf miners

To study the genetic basis of milkweed resistance traits and their relationship to attack by adult Tetraopes and leaf miners, I established a common garden in 2001, employing 26 full-sib families. Families were established from seeds of a single fruit collected along a transect spanning the 350-ha field station; no two families were established from the same parent plant. Approximately 20 individuals from each full-sib family were grown in 500-mL pots in growth chambers for one month before they were planted in the field. Seedlings were planted into a plowed field at Jokers Hill in 4-L plastic pots with field soil. Each pot was completely sunk into the ground and the plants were fully randomized within the common garden.
In July 2002, all surviving plants were censused for adult Tetraopes three times over a two-week period. I report the effects on the sum of Tetraopes observed on each plant over those three dates. Tetraopes adults are locally quite mobile and were dense in the study plot; thus, it is unlikely that individuals remained on plants over the censuses and were counted twice. Leaf miners were counted as successful initiation of mines in leaves. In addition, I measured seven plant resistance, nutritional, and growth traits on all of the plants: production of latex (Appendix A), cardenolides (Appendix A), percentage nitrogen in leaves (Appendix A), foliar trichome density, leaf toughness, maximum plant height, and reproductive status (flowering or not flowering). All measures except for reproductive status were taken from a young, fully expanded leaf. Trichome density on the leaves was assessed by counting them on the tops and bottoms of leaf discs $\left(28 \mathrm{~mm}^{2}\right)$ under a dissecting microscope. I measured leaf toughness with a force-gauge penetrometer (Type 516, Chatillon, New York, New York, USA) that measures the grams of force needed to penetrate a surface. Two measures were taken for each leaf, one on each side of the mid-rib, and these data were averaged and used as a single data point per plant.

In total, 524 plants from 23 families were included in the final analysis (in three families, five or fewer plants survived the transplant and the families were not included in the analysis). One-way ANOVA was used to test for genetic variation in these traits (except for flowering, for which a $G$ test was employed). Subsequently, family-level (full-sib) means were calculated for all of the traits, and a stepwise multiple regression with backward removal ( $P$ value of 0.15 to enter or remove) was employed to detect the influence of the six traits on the abundance of adult Tetraopes and leaf miners. Although this analysis on genetic family means has relatively low power ( $n=23$ family means averaged from 524 plants), the associations reveal the effects of plant genetic variation and suggest possible responses following natural selection. Covariance between the predictor variables was minimal; the only significant correlation was between percentage flowering and maximum height $(r=0.43, P=0.04)$. Results of the multiple regression are essentially identical with one of these traits removed; thus I present the full model here.

\section{RESUlts}

\section{Effects of grass competition on herbivory}

In the first census of herbivory on milkweed plants, before Tetraopes larvae were introduced to roots, milkweed plants next to grass had a $10 \%$ higher attack rate than milkweeds without grass neighbors (control, 22.3 $\pm 0.58 \%$; with grass neighbor, $24.2 \pm 0.56 \%$, mean \pm $1 \mathrm{SE}$; for grass neighbor effect, $F_{1,125}=5.61, P=0.019$; for plant family, $\left.\chi^{2}=1.2, P=0.137\right)$. This effect of 
grass neighbors persisted when milkweed plant height was included as a covariate in the model $\left(F_{1,124}=4.07\right.$, $P=0.046)$, indicating that an effect of grass competition on plant height did not mediate the effect on foliar herbivory. This effect of grass competition on herbivory persisted at the end of the second growing season (Appendix B). In this case, grass competition increased herbivory significantly from $20 \%$ to $26 \%$, and root herbivory did not affect foliar damage. Milkweed plant families strongly varied in the percentage of leaves with damage, indicating genetic variation for resistance $(P<0.001$; Appendix B). Again, the effect of grass neighbors on herbivory persisted when plant height or number of leaves was included as a covariate in the model (all $P$ 's $<0.03$ ).

Even though I ruled out effects of plant height on foliar herbivory by Tetraopes, the effect of grass competition on Tetraopes could have been mediated by some other change in the plant (i.e., trait-mediated effect). To distinguish between trait-mediated and associational effects, I conducted choice tests in which $\mathrm{Te}$ traopes could choose between milkweeds alone and milkweeds with cut grass stems added to the pot. In nearly $70 \%$ of the trials, I found greater levels of herbivory on the milkweeds next to grass stems than on solo milkweeds after 48 hours (Adjusted $G=3.93, P$ $=0.048)$. Thus, the effect of grass neighbors on foliar herbivory by Tetraopes appears to be caused, at least in part, by grasses attracting beetles, not by a traitmediated effect.

Competition was predicted to reduce resources and thus to reduce milkweed resistance to other herbivores in the community, such as leaf miners. Although competition and root herbivory had negligible independent effects on miners, the combined impact of competition and root herbivory resulted in a $40 \%$ reduction in the abundance of leaf miners compared to controls (interaction term $P=0.043$; Fig. 3a, Appendix B). Thus, induced resistance to leaf miners caused by Tetraopes root herbivory was only detected when plants experienced competition. The effects of root herbivory and the interaction with grass on leaf miners persisted when number of leaves or plant height was included in the analysis as a covariate (all $P$ 's $<0.05$ ).

The consequences of plant competition and root herbivory for leaf miners were not associated with changes in the defensive traits that I measured (Appendix C). The only significant effect explaining variation in latex was plant family $(P<0.001)$, which showed nearly 10 -fold variation. My analysis revealed no effect of treatments or family on cardenolide concentrations (Appendix C), and cardenolides in individual plants did not correlate with leaf miner abundance $(r=0.03, n$ $=132, P=0.728)$. Herbivory and competition interacted to influence leaf nitrogen concentrations (Interaction term $P=0.037$; Fig. 3b, Appendix C); carbon was unaffected. Although, on average, the highest leaf miner abundance was found on plants with the lowest
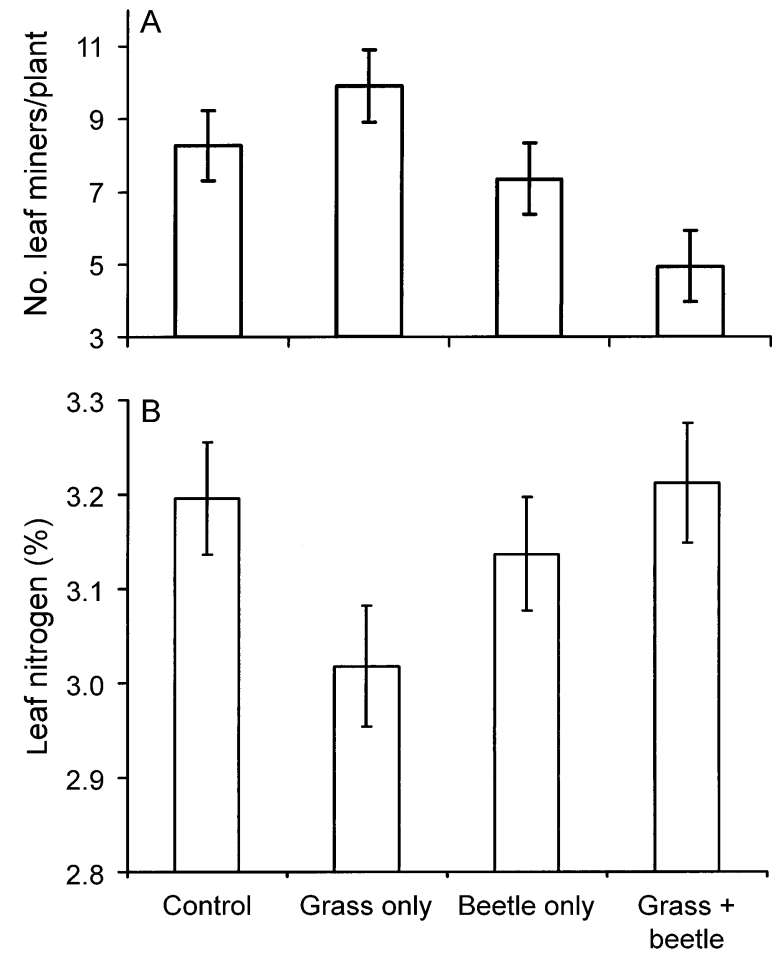

FIG. 3. The effect of competition from grass and root herbivory by Tetraopes on (A) the abundance of the milkweed leaf miner, Liriomyza asclepiadis, and (B) the nitrogen content of leaves. Bars are means \pm 1 SE.

nitrogen content (Fig. 3), there was an overall weak positive correlation between nitrogen and miner abundance $(r=0.20, n=132, P=0.025)$.

\section{Effects of competition and root herbivory on milkweed performance}

In addition to possible competition for soil resources, grass neighbors imposed a $40-60 \%$ reduction in photosynthetically active light reaching milkweeds at the three measurement times (all $P$ 's $<0.001$; Appendix D). By the end of the first growing season, however, neither grass competition nor root herbivory independently affected plant height (control, $27.7 \pm 1.1 \mathrm{~cm}$; competition, $28.2 \pm 1.1 \mathrm{~cm}$; root herbivory, $29.1 \pm$ $1.1 \mathrm{~cm}$, mean $\pm 1 \mathrm{SE})$, but the combined effect reduced plant height by $7 \%$ (competition and herbivory, 25.7 $\pm 1.1 \mathrm{~cm}$; interaction term $P=0.019$; Appendix E). Full-sibling milkweed families also varied in their height by $>40 \%$, with the extreme families ranging from $24.1 \pm 1.2$ to $34.5 \pm 2.4 \mathrm{~cm}$ in height $(P<0.001$; Appendix E).

During the spring of the second growing season, at the time when Tetraopes were completing development, I again detected significant interactions between competition and root herbivory for the three early-season growth parameters: number of stems, stem height, and stem width (Fig. 4, Appendix F). Surprisingly, the interaction term in the MANOVA was only marginally 

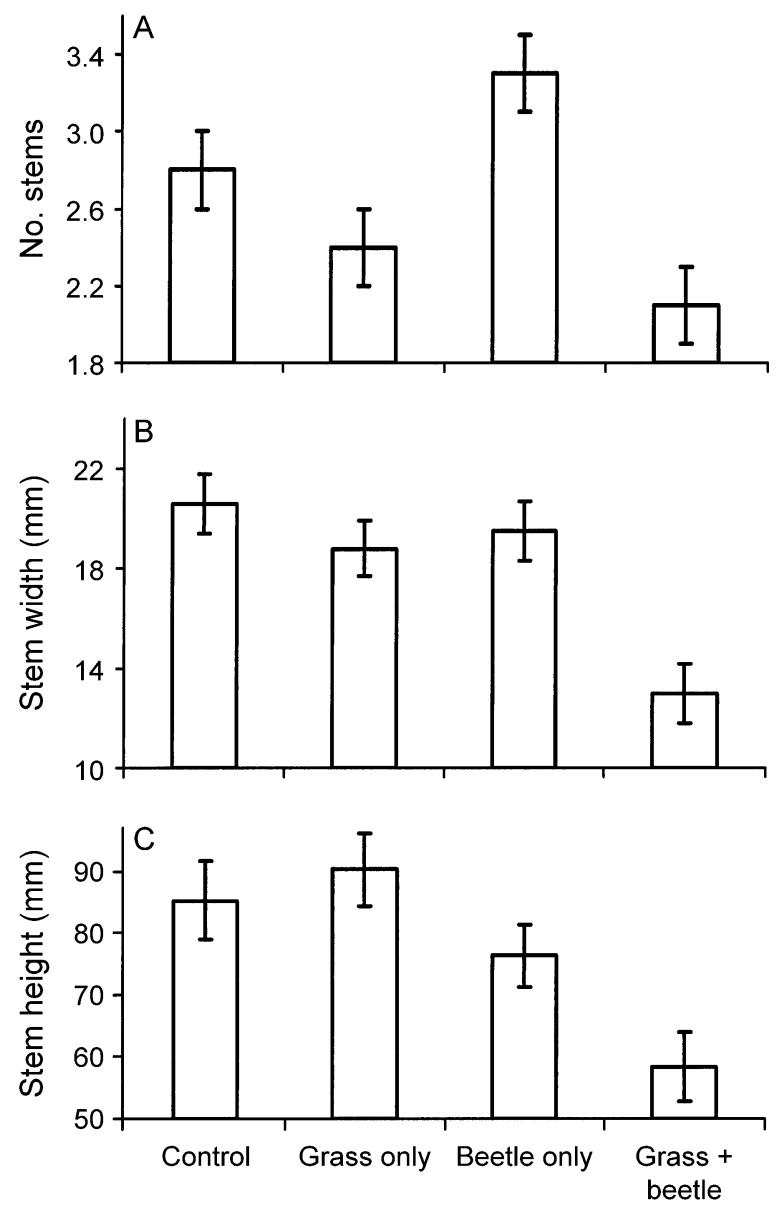

FIG. 4. The effect of competition from grass and root herbivory by Tetraopes on the (A) number, (B) sum of the widths, and (C) sum of the heights of the milkweed stems that emerged in spring of the second season of growth. Bars are means \pm 1 SE for untransformed values.

significant at $P=0.1$, even though each of the univariate analyses revealed a significant interaction (all $P$ 's $<0.03$; Appendix F). This was apparently caused by different types of biological interactions occurring for the three traits. For stem widths and heights, competition and root herbivory had negligible independent effects, whereas the combined effect was strongly negative (Fig. 4). However, for the number of emerging stems, competition and competition plus herbivory reduced the number of stems by $14 \%$ and $25 \%$, respectively, but root herbivory on its own increased the number of emerging stems by $18 \%$ (Fig. 4). Root herbivory apparently severs underground stems, which may promote the activation of dormant buds.

Competition and herbivory had essentially the same effect on each of the three reproductive measures (vegetative biomass, fruit number, and mass per fruit). I found strong effects of root herbivory on all reproductive measures, with highly significant reductions ranging from $16 \%$ to $22 \%$ compared to controls (Fig.
5, Appendix G). Effects of competition and full-sibling family were weak at best, and I did not detect any significant competition by root herbivory interactions for the plant reproductive measures (Fig. 5, Appendix $\mathrm{G)}$.

\section{Effects of competition and herbivory on grass}

Bromus inermis experienced competition from milkweed, and its biomass was reduced by $23 \%$ when growing next to herbivore-free milkweeds, compared to growth in the absence of milkweed for two years (overall ANOVA: $F_{2,100}=4.84, P=0.010$; Fig. 6 ). However, this competitive effect was almost completely alleviated in the presence of host-specific root herbivory by Tetraopes on milkweeds (Fig. 6). Thus, if grasses attract root herbivores of milkweed, the grasses can grow relatively unimpeded by compeition.

\section{Genetic variation in milkweed affects abundance of Tetraopes adults and leaf miners}

Each of the seven predictor variables showed considerable variation among full-sibling families of milk-
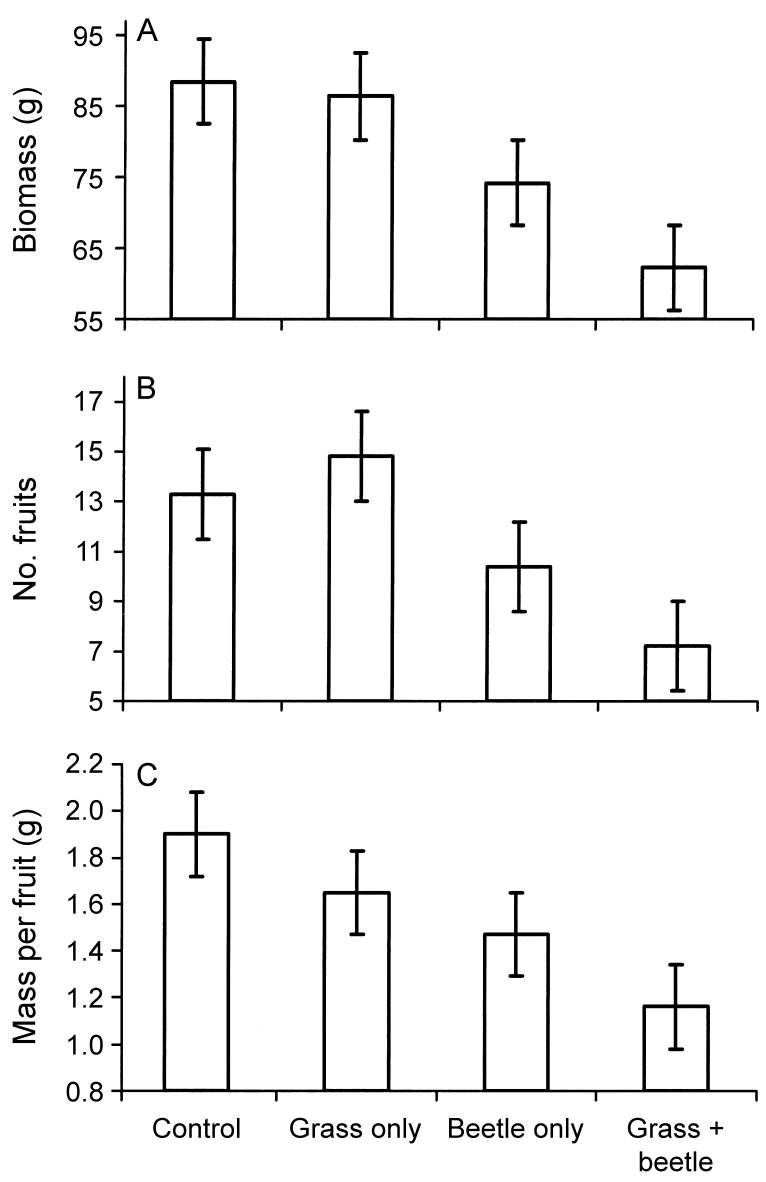

FIG. 5. The effect of competition from grass and root herbivory by Tetraopes on the (A) aboveground vegetative biomass, (B) number of fruits, and (C) mass per fruit of the milkweed plants at the end of the second year of growth. Bars are means \pm 1 SE for untransformed values. 


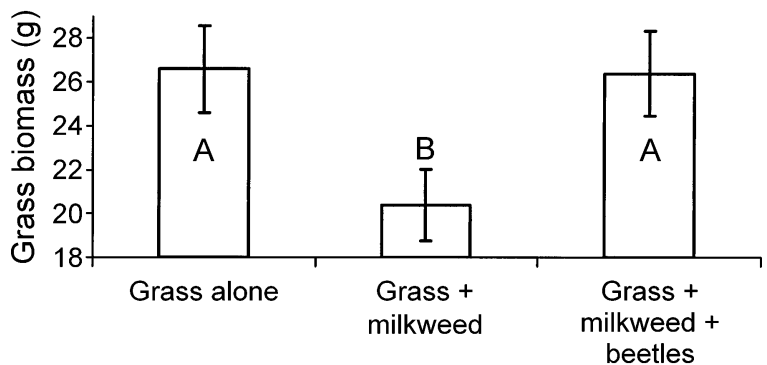

FIG. 6. The effect of competition from milkweed and competition plus host-specific root herbivory by Tetraopes (on milkweed) on aboveground biomass of grass. Bars are means \pm 1 SE. Different letters represent significant differences at $P=0.05$ using Tukey's hsd test.

weed (all $P$ 's $<0.002$; see $x$-axes in Fig. 7). Tetraopes abundance varied nearly sevenfold across plant families $\left(F_{22,499}=2.266, P<0.001\right.$; Fig. 7$)$. In the overall stepwise multiple regression, employing genetic family means, the model explained $83 \%$ of the variance in Tetraopes abundance and only dropped two predictor variables: cardenolide content and leaf toughness
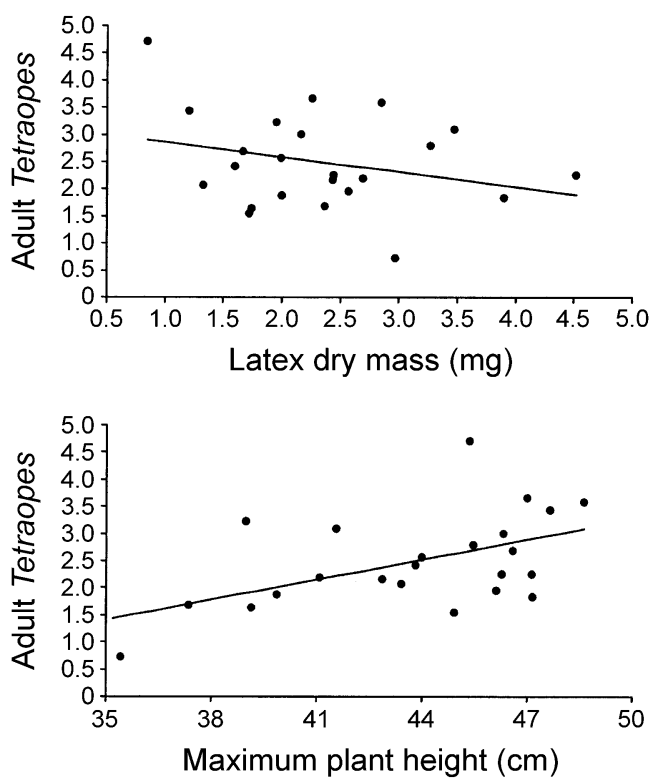

(overall model, $\left.F_{5,17}=17.013, P<0.001\right)$. In terms of putative defensive traits, latex production and trichome density were negatively correlated with Tetraopes abundance (Fig. 7, Appendix H). Surprisingly, leaf nitrogen content was negatively associated with Tetraopes abundance. In addition, both maximum plant height and the probability of flowering (which were correlated) strongly positively influenced the probability of Tetraopes colonizing the plants (Appendix H).

Leaf miner abundance varied over fourfold across plant families $\left(F_{22,501}=2.056, P<0.003\right.$; Fig. 8). In the multiple regression analysis $\left(r^{2}=0.38, F_{2,20}=\right.$ $6.249, P=0.008)$, latex production $(P=0.049)$ and trichome density $(P=0.007)$ predicted leaf miner abundance (Fig. 8); all other factors were dropped in the stepwise regression. The abundance of leaf miners and Tetraopes adults was weakly positively correlated (phenotypic correlation, $r=0.20, F_{1,520}=22.172, P$ $<0.001$; genetic correlation, $r=0.36, F_{1,21}=3.068$, $P=0.094)$.

\section{DISCUSSION}

Although many studies of competition and herbivory typically investigate only one ecological path (Ham-
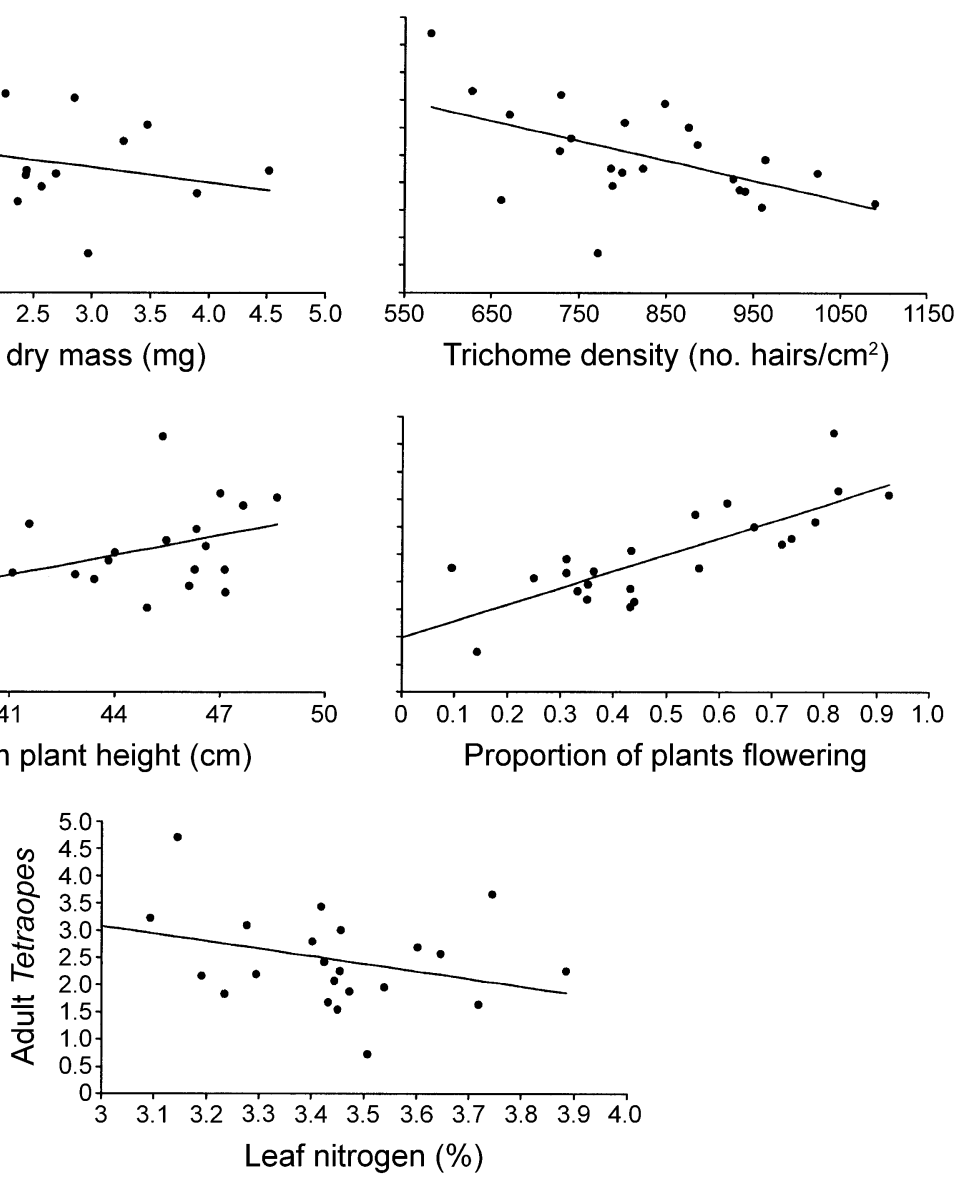

FIG. 7. The effects of latex, leaf trichomes, plant height, the probability of flowering, and leaf percentage nitrogen on the abundance of adult Tetraopes beetles on milkweed. Correlations are based on 23 full-sibling family means, with each dot representing 6-20 individual plants in a common garden. 


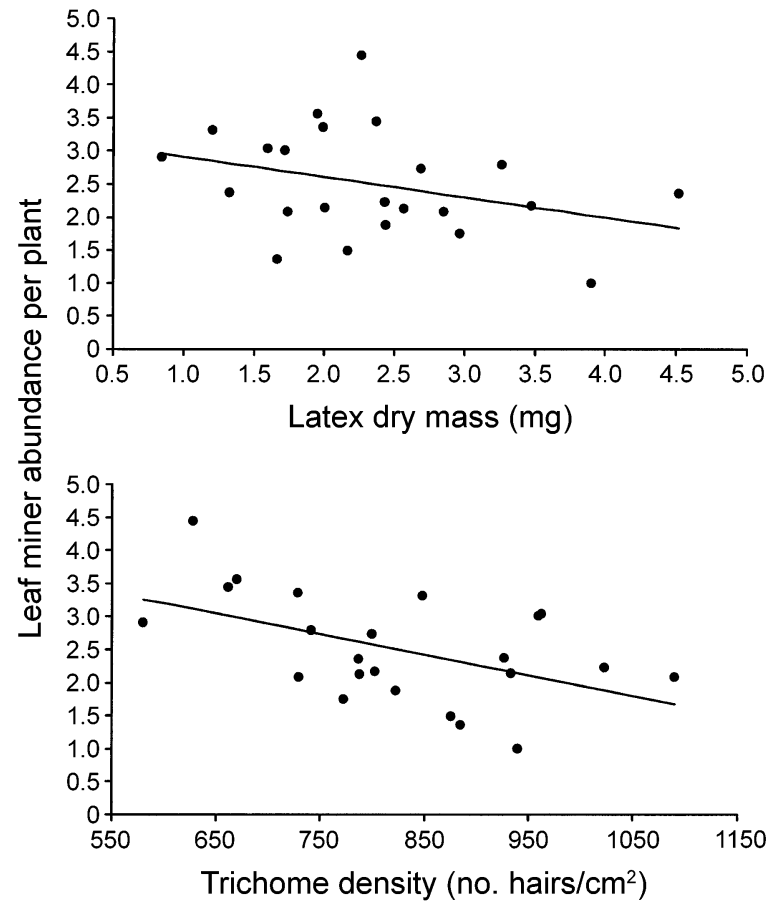

FIG. 8. The effects of latex and leaf trichomes on the abundance of larval leaf miners (Liriomyza asclepiadis) on milkweed. Correlations are based on 23 full-sibling family means, with each dot representing 6-20 individual plants in a common garden.

bäck and Beckerman 2003), the results of the current study demonstrate that even simplified natural communities contain a diversity of simultaneous interactions. I found strong evidence for each of the three paths by which competition and herbivory may interact. The key findings of this study are: (1) neighboring grass stems attract Tetraopes and increase herbivory by this specialist on milkweed; (2) the combination of plant competition and root herbivory cause changes in unknown traits of milkweed, which influence leaf miner abundance on plants; (3) root herbivory and competition interact to synergistically suppress milkweed performance over the first year of growth, but herbivory has a stronger, more long-lasting impact on plant performance measures; (4) the competitive effects of milkweed on grass are completely alleviated by root herbivory on milkweed; and (5) genetic variation in plant traits (i.e., height, flowers, trichomes, latex) influences the abundance of adult beetle herbivores and leaf miners attacking plants.

Very few studies explicitly measure plant-plant interactions in the presence and absence of herbivores (Reader 1992). Two recent studies have taken different approaches to examining the emergent net effects of competition and herbivory. Levine (2000) combined manipulations of neighboring plants with herbivore removals to show that streamside Carex had facilitative effects on neighboring plants during the winter, but competitive and protective (associational resistance) effects during the summer. Taking a more evolutionary approach, Tiffin (2002) showed that herbivory had a greater negative effect on fitness components of Ipomoea purpurea in a high-competition environment compared to a low-competition environment. Nonetheless, plant competition did not affect the pattern of natural selection on plant resistance or tolerance to herbivory (Tiffin 2002). Both of these studies, like mine, measured the competitive effects of plants, the effects of plant association on herbivores, and the net consequences. Ultimately, such a combined approach is necessary to understand how ecological mechanisms result in patterns of plant associations.

\section{Predictions based on models of associational effects, herbivory, and competition}

Root's (1973) original proposal of the resource concentration hypothesis predicted that specialist herbivores were more likely to find host plants in monospecific stands than in mixtures. Thus, associational resistance is predicted to be provided by nonhost plants (e.g., Tahvanainen and Root 1972) and associational susceptibility is more likely for generalist herbivores. This prediction was upheld in Andow's (1991) review of the literature: herbivore densities were lower in plant mixtures compared to monocultures in nearly $60 \%$ of the cases involving monophagous insects; however, for generalist herbivores, only $28 \%$ showed lower densities in polyculture compared to monoculture.

A framework for predicting when associational resistance or susceptibility will be coupled with competitive vs. facilitative effects of plant neighbors on a focal plant is presented in Fig. 9. Much recent work has suggested that species interactions are more likely to be facilitative under environmental stress (Bertness and Callaway 1994, Callaway et al. 2002). Thus, I predict that under stressful conditions, plant-plant interactions will be facilitative, but the indirect consequence of associational resistance or susceptibility will be determined by the diet breadth of the herbivore. The few studies to measure such plant-plant interactions in the presence and absence of herbivores appear to be consistent with my hypothesis (Fig. 9; see Callaway 1992, Hacker and Bertness 1996). In unstressed conditions, plants are likely to compete, but generalists will be more likely to spill over (i.e., migrate from one plant to another) and result in associational susceptibility (Fig. 9; see White and Whitham 2000). Although White and Whitham do not demonstrate competition between cottonwoods and boxelder, the relationship is probably competitive (J. White and T. Whitham, personal communication).

Note that the current study, which finds plant competition and associational susceptibility with a specialist herbivore, does not fit with the predictions (Fig. 9). Indeed, the classification of Tetraopes as a specialist is based on its diet per se, but not on the sum of the 


\section{ENVIRONMENTAL STRESS}

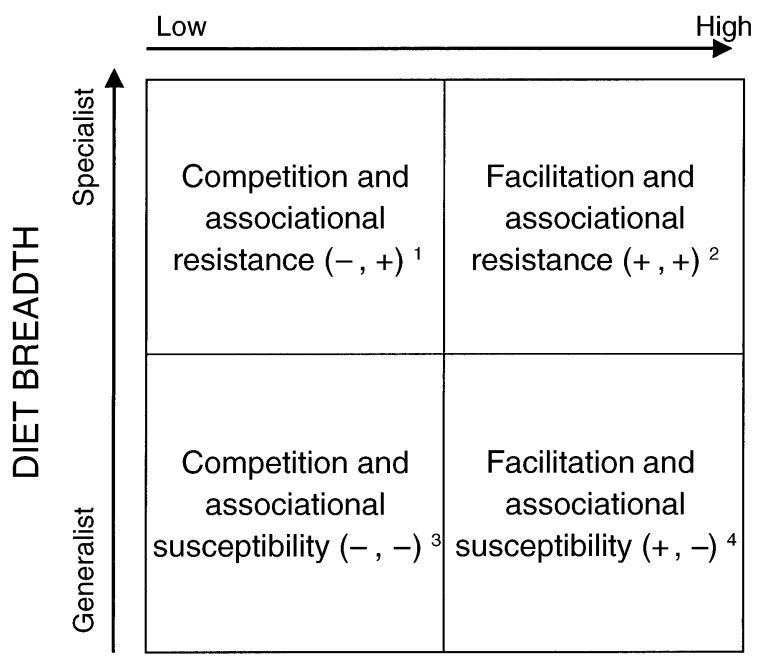

FIG. 9. Plant-plant interactions may result in competition or facilitation and associational resistance or susceptibility. Current models predict that the outcome of plant-plant interactions may be predicted by gradients of environmental stress and the level of specialization of herbivores. These predictions follow logic presented by Root (1973), Andow (1991), Bertness and Callaway (1994), White and Whitham (2000), and Callaway et al. (2002). Many exceptions from these predictions will result from ecological complexities (See Fig. 10). References (indicated by superscript numbers): 1, Levine (2000); 2, Hacker and Bertness (1996); 3, White and Whitham (2000); and 4, Callaway (1992).

resources that it utilizes. Root (1973) foresaw this type of situation, and wrote "Species that must regularly use some special resource (e.g., nighttime shelter, peculiar nutrient in pollen) not available in the pure stand will emigrate." I propose that the simple predictions in Fig. 9, while intuitive, must be elaborated to take into account the level of resources utilized by the herbivore (Fig. 10). The degree to which a specialist or a generalist is affected by neighboring plants will depend on the use of such alternate plants (whether they are hosts or simply providing some other resource). When neighbors provide an essential resource (e.g., oviposition site for Tetraopes) to specialists or a high-quality food to generalists, associational susceptibility should occur because, overall, there is a concentration of resources (Fig. 10). Conversely, nonhost neighbors or poor-quality hosts should result in associational resistance. Because Tetraopes' use of alternative resources is relatively specific (thick grasses or very thin forbs), the composition of the vegetational neighborhood should influence the associational effect. I predict, for example, that most forbs neighboring milkweed will provide milkweed with associational resistance to $T e$ traopes.

In contrast to these predictions, Atsatt and O'Dowd's (1976) Attractant-Decoy hypothesis suggested that highly palatable neighbors would attract and trap gen- eralist herbivores and result in associational resistance for focal plants. However, as previously indicated, the opposite also may hold: associational susceptibility is predicted to occur when herbivores spill over on focal plants from palatable species. Although mechanistic bases for the conditions under which each of these hypotheses is correct have been proposed (i.e., herbivore density, White and Whitham [2000]; patch-use theory, Hjältén et al. [1993]), results for herbivorous insects generally reject the Attractant-Decoy hypothesis and support the notion that palatable neighbors increase herbivory (and unpalatable neighbors reduce herbivory) on focal palatable plants (Hjältén et al. 1993, Wahl and Hay 1995, White and Whitham 2000, Hambäck and Beckerman 2003, Rand 2003, Rousset and Lepart 2003).

\section{Apparent competition in plants}

Some authors recently have suggested that herbivore-mediated apparent competition may occur in plant communities (Connell 1990, Reader 1992, Hambäck and Ekerholm 1997, Rand 2003). In particular, this view follows from Holt's (1977) logic that if two plant species share an herbivore, there may be a reciprocal negative interaction between the two that results from the herbivore building up on the plants. Futuyma and Wasserman (1980) found such a pattern for the fall cankerworm feeding on two oaks: the rarer species within a forest stand suffered greater levels of attack. A similar pattern has been found for Atriplex paluta, which has reduced recruitment when near particular vegetation, because of increased attack by herbivores (Rand 2003). Even though Tetraopes does not consume grass, its requirement for oviposition makes grass an essential resource. Thus, grass imposes a negative effect on milkweed via resource consumption and apparent competition. This nonconsumptive resource use makes apparent competition completely asymmetric

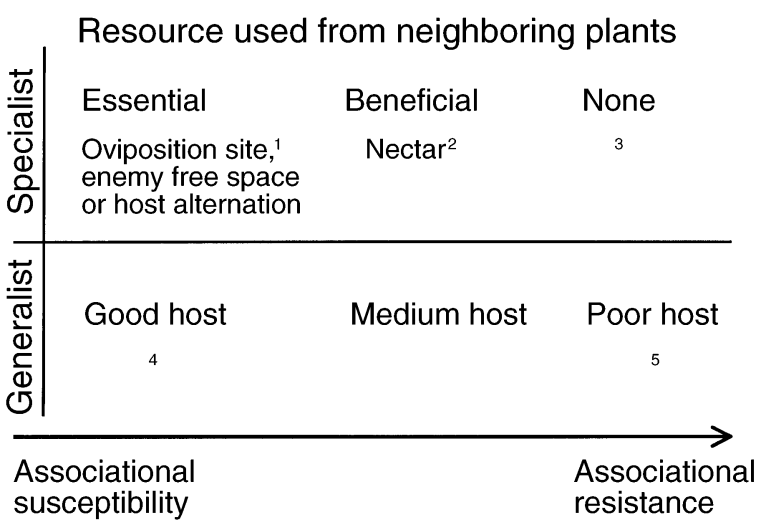

FIG. 10. Associational effects of plant neighbors may be determined not only by the diet breadth of herbivores per se, but also by the extent to which the neighbors are utilized. References (indicated by superscript numbers): 1, this study; 2, Karban (1997); 3, Tahvanainen and Root (1972); 4, White and Whitham (2000); and 5, Wahl and Hay (1995). 
and creates a potential ecological mutualism between the grass and Tetraopes.

The benefits that grass and Tetraopes gain from their interaction result indirectly from the effect of herbivory on milkweed. Because plants are competing for limiting resources, herbivory should provide a benefit to neighbors because herbivory reduces not only plant size, but also the growth function of plants (Rees and Brown 1992). This effect has been shown intraspecifically in the laboratory (van Dam and Baldwin 1998, Agrawal 2000), but to my knowledge has not been previously demonstrated in the field. Most surprising is the fact that root herbivory on milkweeds completely alleviates the competitive effect on grass (Fig. 6). This result has two important implications: (1) a competitive-release "cascade" can occur when potent hostspecific herbivores are facilitated by competitors; and (2) natural selection should favor competitors to attract or enhance the efficacy of the enemies of neighbors. For example, van Dam et al. (2000) proposed that plants growing in close competition might benefit by motivating their herbivores to migrate to neighboring competitors. More generally, the prevalence of competitive-release cascades is unknown. I propose that where competitors frequently meet, and where hostspecific predators and herbivores are also common, organisms should facilitate the enemies of their competitors to achieve a competitive-release cascade.

\section{How competition and herbivory shape the plant defensive phenotype}

Competition and herbivory may affect the plant defensive phenotype independently (via competition- or herbivore-induced responses) and may also interact via competition affecting the inducibility of plants (Karban et al. 1989, Cipollini 2004). The mechanisms by which plant competition influenced Tetraopes herbivory were not mediated via a change in the plant phenotype, but rather were related to the attractive nature of grass neighbors. Although plant competition had little effect on leaf miner abundance independently, plant competition together with root herbivory reduced leaf miner abundance by $40 \%$ compared to controls. This effect is in the opposite direction as that predicted by Karban et al (1989); I found greater induced resistance in plants with competition (which also may have had reduced resources for investment in defense).

The competition-enhanced induced resistance to leaf miners was not associated with changes in leaf number, plant height, latex production, cardenolide content, or leaf carbon. Although overall leaf miner abundance was higher on plants with higher leaf nitrogen content, this did not translate into a treatment (or trait-mediated) effect on nitrogen that influenced leaf miners. An organism's phenotypic response to competition and consumption has strong potential to structure communities, and thus far is little explored (Agrawal 2001, Peacor and Werner 2001, Callaway and Pennings 2003, Werner and Peacor 2003).

In a related study, I examined the role of neighboring grass plants in modifying milkweed morphological traits and subsequent attack by the specialist stem-feeding weevil, Rhyssomatus lineaticollis (Agrawal and Van Zandt 2003). Milkweed plants with their natural grass neighbors removed were released from the classic neighbor avoidance response, having $20 \%$ shorter internode lengths and $90 \%$ thicker stems than controls. Reduction of grass neighbors also resulted in nearly three times the damage and oviposition by weevils, thus supporting the hypothesis of associational resistance being provided by grasses for a (truly) specialized herbivore of milkweed. However, in this case, associational resistance was provided via a trait-mediated indirect influence on resistance, as competition-induced reduction in stem thickness apparently caused reduced attack (Agrawal and Van Zandt 2003). In the current study, stem elongation was not induced by grass neighbors, probably because the milkweeds were much taller than the planted grass seedlings surrounding them.

\section{Interactions between root herbivory and competition on plant performance}

The interaction between root herbivory and plant competition has been investigated for several perennial forbs, and this research has been conducted largely while investigating the biological control of weeds. Lepidopteran or coleopteran herbivores were used in all studies, and four studies involved grass competition (Kok et al. 1986, Müller-Schärer 1991, Steinger and Müller-Schärer 1992, Notzold et al. 1998). Two studies manipulated diverse herbaceous competitors (McEvoy et al. 1993, Sheppard et al. 2001) and two others manipulated intraspecific competition (Müller-Schärer 1991, Maron 2001). Although the current study and that of Notzold et al. (1998) found that herbivory had stronger impacts than competition, the reverse was found by others (Müller-Schärer 1991, Steinger and Müller-Schärer 1992, McEvoy et al. 1993). The intensity of each factor will have to be experimentally varied before generalizations can be attained.

Although interactions between competition and herbivory were found for sporadic plant traits (Kok et al. 1986, Müller-Schärer 1991, McEvoy et al. 1993, Notzold et al. 1998), many of these analyses were not conducted on log-transformed data, and thus interpretation of the multiplicative model was not possible (Rees and Brown 1992, Hambäck and Beckerman 2003). Where interactions were found for growth and reproductive traits, they were typically synergistic; i.e., the combined effects of competition and root herbivory were greater than predicted from their independent effects. For plant mortality, however, substitutive effects were found by Maron (2001), who reported that root herbivores and intraspecific competition independently reduced plant survival by $50 \%$, and their combined 
effects were essentially the same. This finding is consistent with the idea that, for mortality, the two factors act on the same, potentially weak, individuals. However, effects on growth are more likely to be synergistic because herbivores and competitors will each consume whatever resources they can.

For milkweed, non-additive effects of grass competition and Tetraopes herbivory were evident on growth parameters for one year. Although most interactions were synergistic, the increase in stem number following root herbivory was somewhat non-intuitive. A similar result was reported by Müller-Schärer (1991), who found that early instars of a root-boring moth damage the apical meristem and, hence, activate dormant buds. For Asclepias, root herbivory cuts the rhizomelike underground stems, which may allow dormant buds to be similarly activated (Fig. 4A). No significant interactions were detectable for the reproductive parameters measured at the end of the second growing season. Nonetheless, the combination of competition and herbivory had a greater than additive effect (multiplicative model) by $14 \%, 38 \%$, and $9 \%$ for vegetative biomass, fruit number, and mass per fruits, respectively (Fig. 5). This suggests that there may be some potential for synergistic suppression of milkweed by competition and herbivory, possibly depending on the intensity of these stresses. In natural field plots, Matter (2001) found that patches with adult Tetraopes removed had $50 \%$ greater clonal growth (stem number) than plots with beetles left intact.

\section{Genetic variation for plant resistance and possible diffuse coevolution}

In addition to environmental effects on the plant defensive phenotype, I found genetic variation for several resistance traits of milkweed. In particular, plant height and probability of flowering were strongly correlated with abundance of adult Tetraopes. In addition, Hartman (1977) found greater numbers of Tetraopes larvae in soil surrounding flowering milkweeds compared to the soil surrounding nonflowering plants. Given the very strong tendency toward asexual reproduction in A. syriaca (and genetic variation for this trait), it seems reasonable to speculate that Tetraopes may impose natural selection on the mode of reproduction, potentially favoring clonal reproduction over sexual reproduction. Latex and leaf trichome density were negatively associated with Tetraopes abundance. Latex varied nearly 10 -fold across the full-sib families of milkweed, whereas trichome density varied twofold across families; both of these traits may represent a barrier to consumption. The negative association between leaf nitrogen content and Tetraopes abundance is somewhat puzzling, but may represent a correlation between nitrogen content and an unmeasured defensive trait.

Iwao and Rausher (1997) proposed that if a third species modifies the rate or strength of reciprocal selection between two species, then any coevolution that occurs will be diffuse. In particular, they outlined three conditions for diffuse coevolution: (1) correlated susceptibilities to different antagonists; (2) presence of one antagonist affects the damage imposed by another antagonist; and (3) the fitness impact of one antagonist depends on the presence of another antagonist. Although any one of these conditions is sufficient for diffuse coevolution, we have presented evidence for each of them in this study. In the interaction between Tetraopes and milkweed, the biotic neighborhood is likely to strongly alter the evolutionary relationships. The presence of grass, for example, may intensify natural selection imposed by beetles. Because both grasses and Tetraopes, facilitated by grass, have a negative impact on milkweed, the most effective milkweed defense may be a tactic that reduces grass competition (i.e., allelopathy), which indirectly reduces herbivory.

We know much less about the natural and evolutionary history of the specialist leaf-mining fly that attacks milkweed. In addition to environmental effects, latex and trichomes were negatively genetically correlated with miner abundance. Thus, any evolutionary interaction between milkweed and leaf miners is likely to be influenced by: (1) trait-mediated interactions imposed by plant-plant competition and Tetraopes herbivory; (2) genetic variation in latex and trichomes; and (3) the positive correlation of Tetraopes and leaf miner attack. Leaf miner involvement in diffuse coevolution is likely because the presence of another species may modify the strength of selection (Stinchcombe and Rausher 2001).

\section{Concluding speculation}

The natural history of Tetraopes herbivory on milkweed indicates that the environment, in this case the vegetational neighborhood, should strongly influence the interaction. Indeed, I found that, in addition to genetically determined resistance in milkweed, the vegetational neighborhood influenced herbivory in complex ways via direct attraction of herbivores, changing traits of milkweed, and synergistic effects on plant growth.

Although idiosyncratic, like all biological systems, the extreme association between milkweed and Tetraopes has led me to predictions about the conditions under which particular interactions will occur (Fig. 10). In high-nutrient, successional old-fields, competition dominates plant-plant interactions. However, the strength of this competition may be modified by associational effects. Where herbivores are broadly generalized feeders or where specialists make use of resources produced by a diversity of plants, associational susceptibility is likely to result for focal plants next to tasty neighbors. The compounding effects of resource competition and associational susceptibility are likely to increase the speed of succession and intensify natural selection on focal plants. Conversely, when herbivores are true specialists, or when generalists encounter poor- 
quality neighboring plants, associational resistance is likely to reduce the negative effects of resource competition. Depending on the strength of these opposing factors, plant diversity may be maintained, succession may be slowed, and herbivores may have a reduced selective impact on plants.

\section{ACKNOWLEDGMENTS}

I thank Rowan Barrett, Leo Frid, Lisa Plane, Karin Rotem, Jennifer Thaler, Pete Van Zandt, and the Jokers Hill staff for help with fieldwork; Steve Malcolm and Kevin Delaney for tips on measuring cardenolides; Steve Matter for information on working with Tetraopes; Deborah Tam for laboratory assistance and conducting the carbon-nitrogen analyses; Josh Haag for discussion and references; and J. C. Cahill, Bob Denno, William Godsoe, Marc Johnson, Nile Kurashige, Cesar Rodriguez-Saona, Jennifer Thaler, Pete Van Zandt, and anonymous reviewers for comments on the manuscript. My research and laboratory are supported by the Natural Sciences and Engineering Research Council of Canada, Koffler Scientific Reserve at Jokers Hill, Canadian Foundation for Innovation, and a Premier's Research Excellence Award from the government of Ontario.

\section{Literature Cited}

Abrams, P. A. 1995. Implications of dynamically variable traits for identifying, classifying, and measuring direct and indirect effects in ecological communities. American Naturalist 146:112-134.

Agrawal, A. A. 2000. Benefits and costs of induced plant defense for Lepidium virginicum (Brassicaceae). Ecology 81:1804-1813.

Agrawal, A. A. 2001. Phenotypic plasticity in the interactions and evolution of species. Science 294:321-326.

Agrawal, A. A., AND S. B. Malcolm. 2002. Once upon a milkweed. Natural History 111(7):48-53.

Agrawal, A. A., and P. A. Van Zandt. 2003. Ecological play in the coevolutionary theater: genetic and environmental determinants of attack by a specialist weevil on milkweed. Journal of Ecology 91:1049-1059.

Andow, D. A. 1991. Vegetational diversity and arthropod population response. Annual Review of Entomology 36: 561-586.

Atsatt, P. R., and D. J. O’Dowd. 1976. Plant defense guilds. Science 193:24-29.

Bertness, M. D., and R. Callaway. 1994. Positive interactions in communities. Trends in Ecology and Evolution 9:191193.

Brower, L. P., D. R. Kust, E. Rendon-Salinas, E. G. Serrano, K. R. Kust, J. Miller, C. F. d. Rey, and K. Pape. 2004. Catastrophic winter storm mortality of monarch butterflies in Mexico in January 2002. In K. M. Oberhauser and M. Solensky, editors. The Monarch butterfly: biology and conservation: Cornell University Press, Ithaca, New York, USA, in press.

Callaway, R. M. 1992. Effect of shrubs on recruitment of Quercus douglasii and Quercus lobata in California. Ecology 73:2118-2128.

Callaway, R. M., et al. 2002. Positive interactions among alpine plants increase with stress. Nature 417:844-848.

Callaway, R. M., and S. C. Pennings. 2003. Phenotypic plasticity and interactions among plants. Ecology 84:11151128.

Cipollini, D. 2004. Stretching the limits of plasticity: can a plant defend against both competitors and herbivores? Ecology 85:28-37.

Cipollini, D. F., and J. Bergelson. 2001. Plant density and nutrient availability constrain constitutive and wound-in- duced expression of trypsin inhibitors in Brassica napus. Journal of Chemical Ecology 27:593-610.

Connell, J. H. 1990. Apparent versus "real" competition in plants. Pages 9-26 in J. B. Grace and D. Tilman, editors. Perspectives on plant competition. Academic Press, San Diego, California, USA.

Dormann, C. F., R. Van der Wal, and J. P. Bakker. 2000. Competition and herbivory during salt marsh succession: the importance of forb growth strategy. Journal of Ecology 88:571-583.

Dussourd, D. E. 1999. Behavioral sabotage of plant defense: do vein cuts and trenches reduce insect exposure to exudate? Journal of Insect Behavior 12:501-515.

Farrell, B. D., and C. Mitter. 1998. The timing of insect/plant diversification: might Tetraopes (Coleoptera: Cerambycidae) and Asclepias (Asclepiadaceae) have co-evolved? Biological Journal of the Linnean Society 63:553-577.

Friedli, J., and S. Bacher. 2001. Direct and indirect effects of a shoot-base boring weevil and plant competition on the performance of creeping thistle, Cirsium arvense. Biological Control 22:219-226.

Futuyma, D. J., and S. S. Wasserman. 1980. Resource concentration and herbivory in oak forests. Science 210:920922.

Gardiner, L. 1961. A note on the oviposition and larval habits of the milkweed beetle, Tetraopes tetraophthalmus Forst. (Coleoptera: Cerambycidae). Canadian Entomologist 93: 678-679.

Gold, J. J., and J. S. Shore. 1995. Multiple paternity in Asclepias syriaca using a paired-fruit analysis. Canadian Journal of Botany 73:1212-1216.

Goldberg, D. E., and A. M. Barton. 1992. Patterns and consequences of interspecific competition in natural communities - a review of field experiments with plants. American Naturalist 139:771-801.

Gurevitch, J., J. A. Morrison, and L. V. Hedges. 2000. The interaction between competition and predation: a metaanalysis of field experiments. American Naturalist 155: 435-453.

Hacker, S. D., and M. D. Bertness. 1996. Trophic consequences of a positive plant interaction. American Naturalist 148:559-575.

Hairston, N. G., F. E. Smith, and L. B. Slobodkin. 1960. Community structure, population control, and competition. American Naturalist 94:421-425.

Hambäck, P. A., J. Agren, and L. Ericson. 2000. Associational resistance: insect damage to purple loosestrife reduced in thickets of sweet gale. Ecology 81:1784-1794.

Hambäck, P. A., and A. P. Beckerman. 2003. Herbivory and plant resource competition: a review of two interacting interactions. Oikos 101:26-37.

Hambäck, P. A., and P. Ekerholm. 1997. Mechanisms of apparent competition in seasonal environments: an example with vole herbivory. Oikos 80:276-288.

Harris, P. 1981. Stress as a strategy in the biological control of weeds. Pages 333-340 in G. C. Papavizas, editor. Biological control in crop protection-BARC Symposium 5. Allenheld Press, Totowa, New Jersey, USA.

Hartman, F. 1977. The ecology and coevolution of common milkweed (Asclepias syriaca) and milkweed beetles (Tetraopes tetraophthalmus: Cerambycidae). Dissertation. University of Michigan, Ann Arbor, Michigan, USA.

Herrera, J. 1991. Herbivory, seed dispersal, and the distribution of a ruderal plant living in a natural habitat. Oikos 62:209-215.

Hjältén, J., K. Danell, and L. Ericson. 1994. The impact of herbivory and competition on the phenolic concentration and palatability of juvenile birches. Oikos 71:416-422.

Hjältén, J., K. Danell, and P. Lundberg. 1993. Herbivore avoidance by association-vole and hare utilization of woody-plants. Oikos 68:125-131. 
Holt, R. D. 1977. Predation, apparent competition, and structure of prey communities. Theoretical Population Biology 12: $197-229$.

Holt, R. D., and B. P. Kotler. 1987. Short-term apparent competition. American Naturalist 130:412-430.

Iwao, K., and M. D. Rausher. 1997. Evolution of plant resistance to multiple herbivores: quantifying diffuse coevolution. American Naturalist 149:316-335.

Jansen, M. P. T., and N. E. Stamp. 1997. Effects of light availability on host plant chemistry and the consequences for behavior and growth of an insect herbivore. Entomologia Experimentalis et Applicata 82:319-333.

Karban, R. 1993. Induced resistance and plant density of a native shrub, Gossypium thurberi, affect its herbivores. Ecology 74:1-8.

Karban, R. 1997. Neighbourhood affects a plant's risk of herbivory and subsequent success. Ecological Entomology 22:433-439.

Karban, R., and I. T. Baldwin. 1997. Induced responses to herbivory. University of Chicago Press, Chicago, Illinois, USA.

Karban, R., A. K. Brody, and W. C. Schnathorst. 1989. Crowding and a plant's ability to defend itself against herbivores and diseases. American Naturalist 134:749-760.

Kok, L. T., T. J. McEvoy, and W. T. Mays. 1986. Impact of tall fescue grass and Carduus thistle weevils on the growth and development of musk thistle (Carduus nutans). Weed Science 34:966-971.

Levine, J. M. 2000. Complex interactions in a streamside plant community. Ecology 81:3431-3444.

Louda, S. M., K. H. Keeler, and R. D. Holt. 1990. Herbivore influences on plant performance and competitive interactions. Pages 413-444 in J. B. Grace and D. Tilman, editors. Perspectives on plant competition. Academic Press, San Diego, California, USA.

Malcolm, S. B. 1991. Cardenolide-mediated interactions between plants and herbivores. Pages 251-296 in G. A. Rosenthal and M. R. Berenbaum, editors. Herbivores: their interactions with secondary plant metabolites. Second edition. Volume I. The chemical participants. Academic Press, San Diego, California, USA.

Maron, J. L. 2001. Intraspecific competition and subterranean herbivory: individual and interactive effects on bush lupine. Oikos 92:178-186.

Marquis, R. J. 1992. Selective impact of herbivores. Pages 301-325 in R. S. Fritz and E. L. Simms, editors. Plant resistance to herbivores and pathogens. University of Chicago Press, Chicago, Illinois, USA.

Maschinski, J., and T. G. Whitham. 1989. The continuum of plant responses to herbivory-the influence of plant-association, nutrient availability, and timing. American Naturalist 134:1-19.

Matter, S. F. 2001. Effects of above and below ground herbivory by Tetraopes tetraophthalmus (Coleoptera: Cerambycidae) on the growth and reproduction of Asclepias syriaca (Asclepidacae). Environmental Entomology 30: 333-338.

Matter, S. F., J. B. Landry, A. M. Greco, and C. D. Lacourse. 1999. Importance of floral phenology and florivory for Tetraopes tetraophthalmus (Coleoptera: Cerambycidae): tests at the population and individual level. Environmental Entomology 28:1044-1051.

McEvoy, P. B., N. T. Rudd, C. S. Cox, and M. Huso. 1993. Disturbance, competition, and herbivory effects on ragwort (Senecio jacobaea) populations. Ecological Monographs 63:55-75.

Morrow, P. A., D. W. Tonkyn, and R. J. Goldburg. 1989. Patch colonization by Trirhabda canadensis (Coleoptera, Chrysomelidae). Effects of plant species composition and wind. Oecologia 81:43-50.
Müller-Schärer, H. 1991. The impact of root herbivory as a function of plant density and competition: survival, growth and fecundity of Centaurea maculosa in field plots. Journal of Applied Ecology 28:759-776.

Notzold, R., B. Blossey, and E. Newton. 1998. The influence of below ground herbivory and plant competition on growth and biomass allocation of purple loosestrife. Oecologia 113:82-93.

Parker, M. A., and R. B. Root. 1981. Insect herbivores limit habitat distribution of a native composite, Machaeranthera canescens. Ecology 62:1390-1392.

Peacor, S. D., and E. E. Werner. 2001. The contribution of trait-mediated indirect effects to the net effects of a predator. Proceedings of the National Academy of Sciences (USA) 98:3904-3908.

Prokopy, R. J., and E. D. Owens. 1983. Visual detection of plants by herbivorous insects. Annual Review of Entomology 28:337-364.

Rand, T. A. 2003. Herbivore-mediated apparent competition between two salt marsh forbs. Ecology 84:1517-1526.

Reader, R. J. 1992. Herbivory as a confounding factor in an experiment measuring competition among plants. Ecology 73:373-376.

Reader, R. J., and S. P. Bonser. 1998. Predicting the combined effect of herbivory and competition on a plant's shoot mass. Canadian Journal of Botany 76:316-320.

Reagel, P. F., M. D. Ginzel, and L. M. Hanks. 2002. Aggregation and mate location in the red milkweed beetle (Coleoptera: Cerambycidae). Journal of Insect Behavior 15: 811-830.

Rees, M., and V. K. Brown. 1992. Interactions between invertebrate herbivores and plant competition. Journal of Ecology 80:353-360.

Root, R. B. 1973. Organization of a plant-arthropod association in simple and diverse habitats: the fauna of collards (Brassica oleracea). Ecological Monographs 43:95-124.

Rousset, O., and J. Lepart. 2003. Neighbourhood effects on the risk of an unpalatable plant being grazed. Plant Ecology 165:197-206.

SAS Institute. 1999. SAS/STAT users guide. Version 8. SAS Institute, Cary, North Carolina, USA.

Scheiner, S. M. 1993. MANOVA: multiple response variables and multispecies interactions. Pages 94-112 in S. M. Scheiner and J. Gurevitch, editors. Design and analysis of ecological experiments. Chapman and Hall, New York, New York, USA.

Sheppard, A. W., M. J. Smyth, and A. Swirepik. 2001. The impact of a root-crown weevil and pasture competition on the winter annual Echium plantagineum. Journal of Applied Ecology 38:291-300.

Sokal, R. R., and F. J. Rohlf. 1995. Biometry. Third edition. Freeman, New York, New York, USA.

Steinger, T., and H. Müller-Schärer. 1992. Physiological and growth responses of Centaurea maculosa (Asteraceae) to root herbivory under varying levels of interspecific plant competition and soil-nitrogen availability. Oecologia 91: 141-149.

Stinchcombe, J. R., and M. D. Rausher. 2001. Diffuse selection on resistance to deer herbivory in the ivyleaf morning glory, Ipomoea hederacea. American Naturalist 158: 376-388

Tahvanainen, J. O., and R. B. Root. 1972. The influence of vegetational diversity on the population ecology of a specialized herbivore, Phyllotreta cruciferae (Coleoptera: Chrysomelidae). Oecologia 10:321-346.

Thomas, C. D. 1986. Butterfly larvae reduce host plant survival in vicinity of alternative host species. Oecologia 70: 113-117.

Tiffin, P. 2002. Competition and time of damage affect the pattern of selection acting on plant defense against herbivores. Ecology 83:1981-1990. 
van Dam, N. M., and I. T. Baldwin. 1998. Costs of jasmonateinduced responses in plants competing for limited resources. Ecology Letters 1:30-33.

van Dam, N. M., K. Hadwich, and I. T. Baldwin. 2000. Induced responses in Nicotiana attenuata affect behavior and growth of the specialist herbivore Manduca sexta. Oecologia 122:371-379.

Visser, J. H. 1986. Host odor perception in phytophagous insects. Annual Review of Entomology 31:121-144.

Wahl, M., and M. E. Hay. 1995. Associational resistance and shared doom: effects of epibiosis on herbivory. Oecologia 102:329-340.
Werner, E. E., and S. D. Peacor. 2003. A review of traitmediated indirect interactions in ecological communities. Ecology 84:1083-1100.

White, J. A., and T. G. Whitham. 2000. Associational susceptibility of cottonwood to a box elder herbivore. Ecology 81:1795-1803.

Young, D. R., and W. K. Smith. 1980. Influence of sunlight on photosynthesis, water relations, and leaf structure in the understory species Arnica cordifolia. Ecology 61:13801390.

\section{APPENDIX A}

Methods for assessing cardiac glycosides, latex, and leaf carbon and nitrogen content are available in ESA's Electronic Data Archive: Ecological Archives E085-063-A1.

\section{APPENDIX B}

Mixed-model analysis of variance table for effects of grass competition, root herbivory by beetles, and full sibling family of milkweed on percent of leaves with damage and leaf miner abundance at the end of the second growing season is available in ESA's Electronic Data Archive: Ecological Archives E085-063-A2.

\section{APPENDIX C}

Mixed-model analysis of variance table for effects of grass competition, root herbivory by beetles, and full sibling family of milkweed on production of latex, cardenolides, and leaf carbon and nitrogen concentrations near the end of the second growing season is available in ESA's Electronic Data Archive: Ecological Archives E085-063-A3.

\section{APPENDIX D}

Effects of grass competition and time of day on photosynthetically active radiation reaching the base of milkweed plants on a clear day is available in ESA's Electronic Data Archive: Ecological Archives E085-063-A4.

\section{APPENDIX E}

Mixed-model analysis of variance table for effects of grass competition, root herbivory by beetles, and full sibling family of milkweed on natural log of final plant height at the end of the first growing season is available in ESA's Electronic Data Archive: Ecological Archives E085-063-A5.

\section{APPENDIX F}

Multivariate analyses followed by mixed-model univariate analyses for effects of grass competition, root herbivory by beetles, and full sibling family of milkweed on the natural log of number of stems, sum of stem heights, and sum of stem widths in the spring of the second growing season is available in ESA's Electronic Data Archive: Ecological Archives E085063-A6.

\section{APPENDIX G}

Multivariate analyses followed by mixed-model univariate analyses for effects of grass competition, root herbivory by beetles, and full sibling family of milkweed on the natural log of final fruit production, mass per fruit, and vegetative biomass at the end of the second growing season is available in ESA's Electronic Data Archive: Ecological Archives E085-063-A7.

\section{APPENDIX H}

Stepwise multiple regression with backwards removal for the effects of plant resistance traits (cardenolides, latex production, trichome density, and leaf toughness) and leaf nitrogen, plant height and percent flowering on abundance of Tetraopes adults is available in ESA's Electronic Data Archive: Ecological Archives E085-063-A8. 